\title{
Factors associated with nutritional outcomes in the mother-child dyad: a population-based cross-sectional study
}

\author{
Tatiane Géa-Horta ${ }^{1}$, Rita de Cássia Ribeiro Silva ${ }^{2, *}$, Rosemeire Leovigildo Fiaccone ${ }^{3}$, \\ Maurício Lima Barreto ${ }^{4}$ and Gustavo Velásquez-Meléndez ${ }^{1}$ \\ 'Department of Maternal Infant and Public Health, School of Nursing, Federal University of Minas Gerais, Belo \\ Horizonte, Minas Gerais, Brazil: ${ }^{2}$ Nutrition Science Department, Nutrition School, Federal University of Bahia, \\ Av. Araújo Pinho no 32, Canela, CEP: 40.1 10-150, Salvador, Bahia, Brazil: ${ }^{3}$ Institute of Mathematics, Federal \\ University of Bahia, Salvador, Bahia, Brazil: ${ }^{4}$ Institute of Public Health, Federal University of Bahia, Salvador, \\ Bahia, Brazil
}

Submitted 17 July 2015: Final revision received 1 December 2015: Accepted 17 March 2016: First published online 28 April 2016

\begin{abstract}
Objective: To estimate factors associated with double burden of nutritional outcomes in the mother-child dyad at the household level (child stunting and/or maternal overweight).

Design: Cross-sectional study using the Brazilian Demographic and Health Survey. Nutritional outcomes were: mother with normal weight and child with normal height; overweight mother and child with normal height; mother with normal weight and short-stature child; and overweight mother and child with short stature (double burden). The child was classified as short when height-for-age $Z$-score was $<-2$ and the mother as overweight when BMI was $\geq 25 \cdot 00 \mathrm{~kg} / \mathrm{m}^{2}$. Socio-economic status, environment, social vulnerability, maternal characteristics and the child's food intake were the exposure factors. The hierarchical approach for multinomial logistic regression modelling was used to assess the associations. Setting: National Demographic and Health Survey of Children and Women conducted in Brazil, 2006-2007.

Subjects: Mother-child dyads ( $n$ 3676).

Results: After adjustments, lower maternal educational level (OR $=3.53 ; 95 \% \mathrm{CI}$ $1 \cdot 33,9.33$ ) and inadequate household (non-masonry house; OR $=2.54 ; 95 \% \mathrm{CI}$ $1.39,4.66)$ were associated with the double burden of malnutrition. Mother's short stature $(\mathrm{OR}=3.41 ; 95 \% \mathrm{CI} 1.76,6.61)$, child's vegetable intake on less than or equal to $4 \mathrm{~d} /$ week $(\mathrm{OR}=2 \cdot 21 ; 95 \% \mathrm{CI} 1.03,4.75)$ and inadequate household (non-masonry house; $\mathrm{OR}=2 \cdot 29 ; 95 \% \mathrm{CI} 1 \cdot 36,3 \cdot 87$ ) were associated with child's short stature. The lack of breast-feeding (OR $=2.00 ; 95 \%$ CI 1.07, 3.72) was associated with maternal overweight.

Conclusions: The present findings contribute to establishing strategies promoting health and healthy diets, by considering the growth deficit and overweight/obesity concomitantly.
\end{abstract}

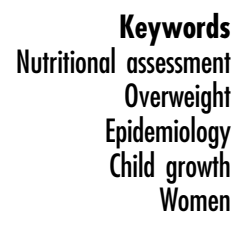

Developing countries have experienced increasing rates of overweight $^{(1,2)}$. In Brazil, increasing prevalence rates of overweight have been observed in the population at all life stages. Overweight was observed in $7.3 \%$ of children under 5 years old $^{(3)}$ and in $33.5 \%$ of children aged 5-9 years ${ }^{(4)}$. Among women, over the course of a 35-year period, overweight increased from $28.7 \%$ in 1974 to $48 \%$ in 2008. In addition, the obesity rate among women increased more than twofold during the same period, from $8 \%$ to $16.9 \%{ }^{(4)}$.

Genetic $^{(5)}$, psychosocial $^{(6)}$ and metabolic ${ }^{(7)}$ factors may be associated with obesity. However, the factors that best explain the growing number of overweight people involve changes in lifestyle ${ }^{(8)}$, the high prevalence of physical inactivity and the increased consumption of processed foods with high energy density, particularly those rich in saturated fat and simple carbohydrates ${ }^{(9)}$.

Unlike overweight, the prevalence of child undernutrition has declined globally over the past decades. However, this reduction in undernutrition is occurring unevenly; in fact, the problem has increased in some countries ${ }^{(10)}$. It is estimated that 186 million children under 5 years of age are affected by protein-energy malnutrition worldwide $^{(10)}$. In Brazil, between 2008 and 2009, 6\% of 
children under 5 years old were malnourished. Social and economic inequities are the main predictive factors of undernutrition $^{(4,11)}$.

In this context, the current scenario of the nutrition transition in poor and developing countries is characterized by the double burden of malnutrition, which refers to under- and overnutrition occurring simultaneously, even within members of the same family ${ }^{(12)}$. High prevalence of the double burden of malnutrition has been increasing in middle- and low-income countries ${ }^{(13)}$. In Guatemala, Argentina and Africa it has been shown that underweight or short stature of the child can coexist with maternal overweight $^{(14-16)}$.

The determinants of these two nutritional phenomena in the same household are well described in the literature ${ }^{(17,18)}$; however, there are few studies assessing the factors associated with the coexistence of this double burden morbidity ${ }^{(19,20)}$. Studies describe that it is associated with low levels of maternal education ${ }^{(16)}$, lower household incomes $^{(13)}$ and environmental factors, which include changes in dietary patterns with intakes of high-energy and nutrient-poor foods ${ }^{(21)}$. Epidemiological evidence also suggests that maternal nutrition during pregnancy may influence the risk of child undernutrition and subsequent obesity in adulthood ${ }^{(22)}$.

The present study was designed because there are few studies investigating factors associated with the coexistence of undernutrition and overweight, two outcomes of an apparently antagonistic nature, among different members of the same family that share the same physical space, and because of the importance of elucidating possible relationships between poorly investigated variables and the variables already known to be involved in the causality network of these nutritional outcomes. Thus, the present study aimed to estimate factors associated with double burden of nutritional outcomes in the mother-child dyad at the household level (child stunting and/or maternal overweight) using data from the Brazilian Demographic and Health Survey.

\section{Methods}

The current cross-sectional study analysed data from the latest National Demographic and Health Survey of Children and Women conducted between 2006 and 2007 in Brazil (Pesquisa Nacional de Demografia e Saúde da Criança e da Mulher; PNDS). The survey is part of the worldwide Demographic and Health Survey (DHS) programme. This nationwide survey was performed using complex probability sampling and its main objective was to provide information on population, family planning and health $^{(3)}$. The sampling plan of the PNDS was designed to provide estimates representative of the Brazilian population living in private households in common or non-special census tracts (including slums), who were selected in ten sampling strata that comprise a combination of all five major geographical Brazilian regions and of both urban and rural areas. The sampling units were selected in two stages: the primary units were composed by census tracts and the secondary units by households ${ }^{(3)}$. Detailed sampling plans, data collection information and data quality assurance are available in the PNDS/DHS 2006 survey final reports (available at http://bvsms.saude. gov.br/bvs/pnds/index.php).

Details about how the databases were related and edited to allow analysis of the mother-child dyad - the outcome of the present study (child with short stature and maternal overweight) - have been described previously $^{(23)}$. Anthropometric measurements of mothers and children were performed according to internationally standardized procedures ${ }^{(24)}$ where two measures were obtained for each anthropometric indicator (weight and height) and the mean value was used. Mothers whose children were, at date of the interview, alive and living with them were included in the current analysis. It is important to highlight that when the mother had more than one child in the house (about 22\%), the eldest child was chosen for the mother-child dyad. This choice was due to the fact that the older child would have longer duration of exposure to deprivation and other factors affecting growth ${ }^{(25)}$. Thus, the final number of mother-child dyad observations was 3676. It should be emphasized that there were no statistically significant differences in socioeconomic and demographic characteristics between the excluded and studied children (data not shown). It is noteworthy that some individuals did not present complete data for all variables used in the analyses.

The stature of the children was classified by the heightfor-age $Z$-score (HAZ), with HAZ $<-2$ considered as short stature $^{(26)}$. Maternal BMI was calculated using the mother's weight in kilograms and height in metres according to the formula weight $/$ height $^{2}$ and $\mathrm{BMI} \geq 25.00 \mathrm{~kg} / \mathrm{m}^{2}$ was considered as overweight ${ }^{(24)}$.

Exposure variables were evaluated in the following levels and blocks according to Fig. 1.

1. Level 1, block A, socio-economic factors: included the variables maternal employment $(0=$ mother did not work outside the household, $1=$ mother worked outside the household), maternal educational level $(0=$ more than 8 years of schooling, $1=$ less than or equal to 8 years of schooling), mother's skin colour $(0=$ white, $1=$ nonwhite), maternal marital status $(0=$ married, $1=$ single/ widowed/divorced), area of residence $(0=$ urban, $1=$ rural $)$, region of residence $(0=$ South, $1=$ Southeast, $2=$ North, $3=$ Northeast, $4=$ Midwest) and economic status assessed by ownership of household goods (based on the Brazilian Economic Classification Criteria of the Brazilian Association of Research Companies (Associação Brasileira de Empresas de Pesquisa) ${ }^{(27)}$, stratified into tertiles, with the third tertile used as the reference). 


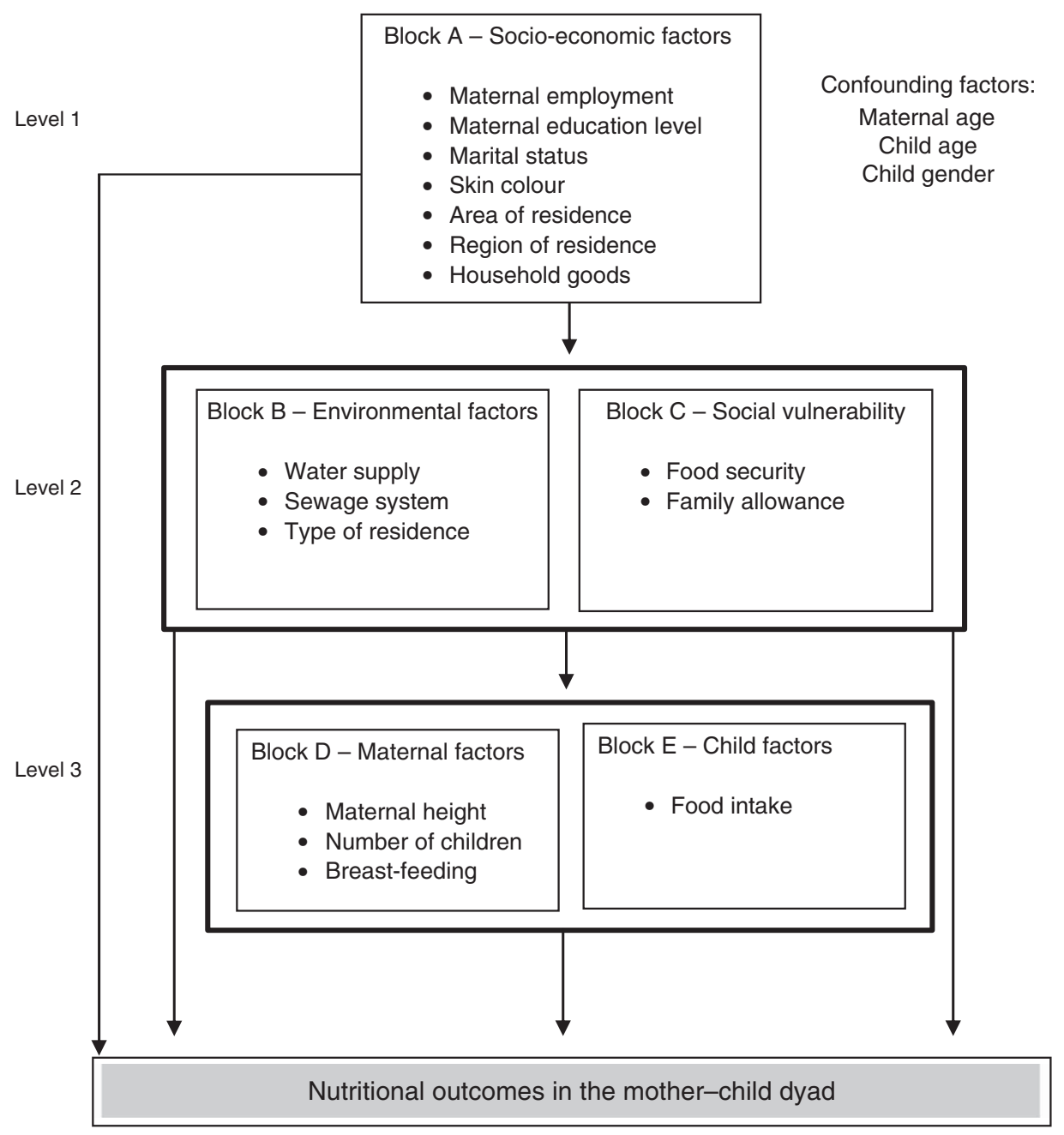

Fig. 1 Conceptual theoretical framework of the possible factors associated with nutritional outcomes in the mother-child dyad

The variable family income was not included in the analysis due to the high number of missing responses.

2. Level 2, block B, environmental factors: included the variables type of residence $(0=$ masonry, $1=$ others $)$, water supply $(0=$ public, $1=$ others $)$ and sewage system ( $0=$ pipe network, $1=$ others $)$. Level 2 , block C, social vulnerability: included the Brazilian Food Insecurity Scale (Escala Brasileira de Insegurança Alimentar; EBIA $)^{(28)}$, represented by scores $(0=$ food security, $1=$ mild food insecurity, $2=$ moderate food insecurity, $3=$ severe food insecurity), and being a beneficiary of the family allowance programme ( $0=$ beneficiary, $1=$ not a beneficiary).

3. Level 3, block D, maternal factors: included maternal height (divided into tertiles, with the third tertile used as the reference), the number of children $(0=1$ child, $1=$ more than one child) and breast-feeding ( $0=$ yes, $1=$ no). Level 3, block E, child's food intake: assessed by the intakes of fruits, vegetables, rice, beans, fish and meat $(0=$ more than $4 \mathrm{~d}$ /week, $1=$ less than or equal to $4 \mathrm{~d} /$ week) and candy, soft drinks and fried foods $(0=$ less than $4 \mathrm{~d} /$ week, $1=$ more than or equal to
$4 \mathrm{~d} /$ week) in the week before the interview. The frequency of consumption was related to the seven days prior to the interview and answer choices for each food item were: not consumed, consumed on one day, two to three days, four to six days, or every day, and do not know $^{(3)}$. We assumed this first group (fruits, vegetables, rice, beans, fish and meat) as a marker of eating healthy foods and the other group, as an unhealthy diet marker. This classification was based on nutritional recommendations for the prevention of chronic diseases and also because there is evidence to suggest the association of these variables with excess weight and other risk factors for chronic diseases, such as dyslipidaemias ${ }^{(29-31)}$. The consumption of these foods was denoted by an indicator that expresses the proportion of children who consumed each of the selected foods more frequently (regularly: at least five of the seven days preceding the study) and less frequently (between zero and four days of the seven days preceding the study); this indicator is already used in the risk factors surveillance system ${ }^{(32)}$. The variable birth weight of the child was not included due to the high number of missing responses. 
The outcome of interest, the mother-child dyad, was ranked into the following four categories.

1. Category 0 (reference): mother with normal weight and child with normal height (NM/NC).

2. Category 1: overweight mother and child with normal height $(\mathrm{OM} / \mathrm{NC})$.

3. Category 2: mother with normal weight and shortstature child (NM/SSC).

4. Category 3: overweight mother and short-stature child (OM/SSC), defined as a double burden of malnutrition.

The descriptive statistics included the estimation of absolute frequencies (sample size), relative frequencies, and means and standard errors. Significant differences were evaluated using the $\chi^{2}$ test based on the sampling design $(P<0 \cdot 05)$. The hierarchical approach for multinomial logistic regression modelling was used to study the factors associated with OM/NC, NM/SSC and OM/SSC. So, the analysis was conducted in accordance with a predefined conceptual model (Fig. 1). The model defined three hierarchical levels: the first (distal) included one block with all socio-economic variables; the second level included two blocks, social vulnerability and environmental variables; and the third (proximal) level included two blocks, one for maternal characteristics and other for children's food intake. We assumed that socio-economic conditions were more distal determinants that may affect an individual's nutritional status directly or partly through determinants in the second level and third level. Then, in accordance with Fig. 1, social vulnerability and environmental variables can influence maternal characteristics such as mother's stature and also children's food intake. Finally, all hierarchically higher variables can contribute to explain the double burden of malnutrition taking into account all interrelationships between them. All models included mother's age and children's gender and age. The covariates from the first level presenting a $P$ value $\leq 0 \cdot 20$ were admitted to the next step of intra-block backward selection and only the covariates with $P$ values $\leq 0.05$ at this second step were included as input in the hierarchical modelling for the third level. This reflects the proposed causal mechanism ${ }^{(33-35)}$ : model $\mathrm{A}$, including the variables of block A, aims to obtain the overall effect of socioeconomic factors; model $\mathrm{B}$, adding to model $\mathrm{A}$ the significant variables of blocks $\mathrm{B}$ and $\mathrm{C}$, estimates the overall effect of the second level, adjusted for confounding in block A; and model $\mathrm{C}$, which adds to model $\mathrm{B}$ the thirdlevel variables, aims to estimate the overall effect of maternal factors and food intake, adjusted for confounding of blocks A-C. Models A, B and C were defined by fitting a sequence of multivariate regression models that kept, at the level last added, only the variables selected, again by backward elimination ( $P$ value $\leq 0.05)$, through a likelihood ratio test.

Data were processed and analysed using the program Statistical Software for Professionals, version 12.1, using the Survey module of the statistical package that considers various aspects of the complex sampling design in the analysis.

Regarding the ethical aspects, the PNDS 2006 was approved by the Research Ethics Committees of the STD/ AIDS Reference and Training Center of the São Paulo State Health Department, São Paulo, Brazil. All individuals who agreed to participate in the study signed an informed consent form.

\section{Results}

Among the total of 3676 mothers who participated in the study, $85.2 \%$ were married or in a stable relationship; $57.6 \%$ reported that they did not work outside the household; $55 \cdot 2 \%$ had less than or equal to 8 years of schooling; $34.1 \%$ had a better economic status; $41.8 \%$ were living in the Southeast region of the country; and $81.4 \%$ were living in urban areas. Moreover, most of them had only one child (78.5\%) and breast-fed their children (96.8\%).

The mean age of the mothers was 27 (SE 0.21) years and the mean maternal BMI was 25 (se 0.15) kg/m² (Table 1$)$. The environmental characteristics and social vulnerability of the studied dyads were also considered. Approximately $64.0 \%$ of households had piped water, while only $47.6 \%$ of households were connected to the sewage network; $87.2 \%$ lived in masonry houses, $75.8 \%$ were not beneficiaries of the family allowance programme and $6.4 \%$ had severe food insecurity (see online supplementary material, Supplemental Table 1).

The mean age of the children was 2 (se 0.03) years and their mean HAZ was 0.28 (se 0.04; Table 1). There was a slightly higher proportion of males ( $52 \%$ ). In addition, $54.4 \%, 72 \cdot 2 \%$ and $67.2 \%$ of the studied children consumed fruits, rice and beans, respectively, on more than $4 \mathrm{~d} /$ week. However, $66.8 \%$ and $83.0 \%$ of them consumed legumes and vegetables, respectively, on less than or equal to $4 \mathrm{~d} /$ week. Other characteristics of the children are shown in the online supplementary material, Supplemental Table 1.

The prevalence of the double burden of malnutrition was 2.2 (95\% CI 0.01, 0.03) \%, of child stunting was 6.4 (95\% CI $0 \cdot 05,0.08) \%$ and of mothers with overweight was $44.2(95 \%$ CI $0.38,0.47) \%$. In addition, 50.9 (95\% CI $0.47,0.53) \%$,

Table 1 Characteristics of the mothers and children in the motherchild dyads ( $n$ 3676), National Demographic and Health Survey of Children and Women, Brazil (PDNS), 2006-2007

\begin{tabular}{lrcc}
\hline Characteristic & Mean & SE & \multicolumn{1}{c}{$95 \% \mathrm{Cl}$} \\
\hline Maternal BMI $\left(\mathrm{kg} / \mathrm{m}^{2}\right)$ & $25 \cdot 02$ & 0.15 & $24 \cdot 70,25 \cdot 33$ \\
HAZ & -0.28 & 0.04 & $-0.37,-0.21$ \\
Age of children (years) & $2 \cdot 16$ & 0.03 & $2 \cdot 09,2 \cdot 24$ \\
Age of mothers (years) & $27 \cdot 17$ & 0.21 & $26.73,27 \cdot 61$ \\
\hline
\end{tabular}

HAZ, height-for-age Z-score. 


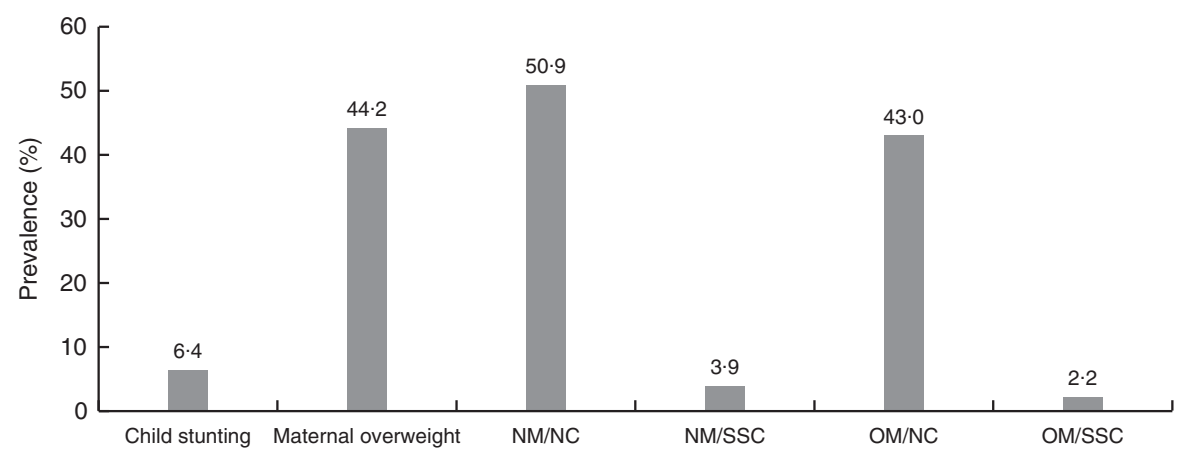

Fig. 2 Prevalence of nutritional outcomes (child stunting and/or maternal overweight) in mother-child dyads ( $n$ 3676) at the household level, National Demographic and Health Survey of Children and Women, Brazil (PDNS), $2006-2007$ (NM/NC, mother with normal weight and child with normal height; NM/SSC, mother with normal weight and short-stature child; OM/NC, overweight mother and child with normal height; OM/SSC, overweight mother and short-stature child - double burden of malnutrition)

43.0 (95\% CI 0.39, 0.46) \% and 3.9 (95\% CI 0.02, 0.05$) \%$ were classified as $\mathrm{NM} / \mathrm{NC}, \mathrm{OM} / \mathrm{NC}$ and $\mathrm{NM} / \mathrm{SSC}$, respectively (Fig. 2).

The results of the analysis of each factor individually associated with the outcome, adjusted for maternal age, age and gender of the child, are shown in the online supplementary material, Supplemental Table 1 . The odds of the double burden of malnutrition were significantly higher among mothers with lower educational level $(\mathrm{OR}=4.54$; $95 \%$ CI 1.84, 11.22), living in inadequate households (non-masonry house; $\mathrm{OR}=3.63$; $95 \%$ CI 1.91, 6.90), living in the Northern region of Brazil (OR $=3.09 ; 95 \%$ CI 1.30 , 7.35), with severe food insecurity (OR $=3.32 ; 95 \%$ CI 1.42 , 7.72), who did not breast-feed (OR $=3 \cdot 07$; $95 \%$ CI $1 \cdot 10$, 8.58) and among children who consumed fried food on more than or equal to $4 \mathrm{~d} /$ week $(\mathrm{OR}=3.03 ; 95 \%$ CI 1.08 , 8.47). The odds of child short stature were significantly higher among whose those mothers had a lower educational level $(\mathrm{OR}=2.46$; 95\% CI 1.31, 4.61), were living in inadequate households (non-masonry house; OR $=3 \cdot 18$; $95 \%$ CI $1.90,5 \cdot 31)$, were living in the Northern region of Brazil (OR $=2 \cdot 62 ; 95 \%$ CI 1.14, 6.02), who were in the first tertile of household goods (OR $=2.97$; $95 \%$ CI 1.52, 5.79), had short stature (OR $=4 \cdot 25 ; 95 \%$ CI $2 \cdot 22,8 \cdot 15)$ and among children who consumed vegetables on less than or equal to $4 \mathrm{~d} /$ week $(\mathrm{OR}=2 \cdot 80 ; 95 \%$ CI $1.31,6.01)$. The odds of maternal overweight were significantly higher among mothers who did not breast-feed their children $(\mathrm{OR}=1.98$; 95\% CI 1.06, 3.70; Supplemental Table 1).

The results of the intra-block analysis of the variables selected in the previous stage are shown in the online supplementary material, Supplemental Table 2. Lower maternal educational level $(\mathrm{OR}=4.76 ; 95 \%$ CI 1.99 , $11.41)$, living in the Northern region of Brazil $(\mathrm{OR}=2 \cdot 80$; $95 \%$ CI $1.17,6.66)$ and in inadequate households (nonmasonry house; OR $=3.63 ; 95 \%$ CI 1.91, 6.90), having severe food insecurity (OR $=2.93 ; 95 \%$ CI $1.09,7 \cdot 80)$, having a higher number of children $(\mathrm{OR}=2 \cdot 19 ; 95 \% \mathrm{CI}$ $1.03,4.66)$ and not breast-feeding (OR $=3.08 ; 95 \%$ CI 1.08 , 8.72) were associated with the double burden of malnutrition. The first $(\mathrm{OR}=2 \cdot 82 ; 95 \% \mathrm{CI} 1.20,6 \cdot 61)$ and second tertile (OR $=2 \cdot 21 ; 95 \%$ CI $1.04,4.68)$ of household goods, living in inadequate households (non-masonry house; $\mathrm{OR}=3 \cdot 18 ; 95 \%$ CI $1.90,5 \cdot 31)$, mothers with low stature $(\mathrm{OR}=4 \cdot 21 ; 95 \% \mathrm{CI} 2 \cdot 19,8 \cdot 09)$ and children who consumed vegetables on less than or equal to $4 \mathrm{~d} /$ week $(\mathrm{OR}=2 \cdot 49$; $95 \%$ CI $1.10,5.61)$ were associated with the category $\mathrm{NM} / \mathrm{SSC}$. Not breast-feeding the child was associated with the category $\mathrm{OM} / \mathrm{NC}(\mathrm{OR}=1.99 ; 95 \% \mathrm{CI} 1.06,3.72)$.

Table 2 shows the final results of multinomial logistic regression analysis using the $\mathrm{NM} / \mathrm{NC}$ category as the reference. Among the socio-economic factors, lower maternal educational level $(\mathrm{OR}=3.53$; $95 \%$ CI 1.33, 9.33) increased to three times the odds of the double burden of malnutrition. Regarding the environmental characteristics, children living in inadequate households (non-masonry house) were more likely to have short stature $(\mathrm{OR}=2 \cdot 29$; $95 \%$ CI $1 \cdot 36,3 \cdot 87)$ and the double burden of malnutrition $(\mathrm{OR}=2.54 ; 95 \%$ CI 1.39, 4.66). Regarding maternal characteristics, mother's short stature (OR $=3.41 ; 95 \%$ CI 1.76 , 6.61) increased the odds of the child having short stature by threefold and mothers who did not breast-feed their children were more likely to be overweight $(\mathrm{OR}=2 \cdot 00$; $95 \%$ CI 1.07, 3.72). Among the variables associated with child nutrition, vegetable intake on less than or equal to $4 \mathrm{~d} /$ week $(\mathrm{OR}=2 \cdot 21 ; 95 \%$ CI $1.03,4.75)$ increased the odds of short stature among children more than twofold.

\section{Discussion}

The current study aimed to estimate factors associated with double burden of nutritional outcomes in the mother-child dyad at the household level (child stunting and/or maternal overweight). In the dyads studied, $2 \cdot 2 \%$ presented the double burden, which is below the rate of $3.3 \%$ reported in a study conducted in fifty-four countries between 1991 and 2009 with children aged 2-5 years old $^{(36)}$. Higher prevalence was shown in Argentina $(12 \%)^{(16)}$ and a study in Algeria reported a rate of $7 \%$ in 
Table 2 Final model of the multinomial regression, with odds ratios and $95 \%$ confidence intervals of the factors associated with the nutritional outcomes in the mother-child dyads ( $n$ 3676), National Demographic and Health Survey of Children and Women, Brazil (PDNS), 2006-2007

\begin{tabular}{|c|c|c|c|c|c|c|c|}
\hline \multirow[b]{2}{*}{ Variable } & \multirow[b]{2}{*}{ Category } & \multicolumn{2}{|c|}{$\mathrm{OM} / \mathrm{NC}$} & \multicolumn{2}{|c|}{ NM/SSC } & \multicolumn{2}{|c|}{ OM/SSC } \\
\hline & & OR & $95 \% \mathrm{Cl}$ & OR & $95 \% \mathrm{Cl}$ & OR & $95 \% \mathrm{Cl}$ \\
\hline \multicolumn{8}{|l|}{ Level 1 - Socio-economic factors block } \\
\hline Maternal educational level (years) & $>8$ (ref.) & - & - & - & - & - & - \\
\hline & $\leq 8$ & $1 \cdot 25$ & $0.97,1.60$ & $1 \cdot 76$ & $0.85,3.63$ & 3.53 & $1 \cdot 33,9 \cdot 33^{*}$ \\
\hline \multicolumn{8}{|l|}{ Level 2 - Environmental factors block } \\
\hline Type of residence & Masonry (ref.) & - & - & - & - & - & \\
\hline & Others & 0.97 & $0.74,1.28$ & $2 \cdot 29$ & $1 \cdot 36,3 \cdot 87^{*}$ & 2.54 & $1.39,4.66^{\star}$ \\
\hline \multicolumn{8}{|l|}{ Level 3 - Maternal factors block } \\
\hline \multirow[t]{3}{*}{ Maternal height (tertile) } & Third (ref.) & - & - & - & - & - & - \\
\hline & Second & 0.86 & $0.63,1.16$ & 1.39 & $0.52,3.70$ & 0.59 & $0.23,1.49$ \\
\hline & First & 1.02 & $0.75,1.39$ & 3.41 & $1 \cdot 76,6 \cdot 61^{*}$ & 1.09 & $0.47,2.53$ \\
\hline \multirow{2}{*}{ Breast-feeding } & Yes (ref.) & - & - & - & - & - & - \\
\hline & No & 2.00 & $1.07,3 \cdot 72^{*}$ & 0.71 & $0.15,3.38$ & $2 \cdot 39$ & $0.79,7 \cdot 26$ \\
\hline \multirow[t]{2}{*}{ Number of children } & One (ref.) & - & - & - & - & - & - \\
\hline & More than one & 0.97 & $0 \cdot 70,1.35$ & $1 \cdot 36$ & $0 \cdot 70,2 \cdot 63$ & 1.66 & $0.74,3.41$ \\
\hline \multicolumn{8}{|l|}{ Level 3 - Child factors block } \\
\hline \multirow[t]{2}{*}{ Vegetables intake (days) } & More than $4 \mathrm{~d} /$ week (ref.) & - & - & - & - & - & - \\
\hline & $\begin{array}{l}\text { Less than or equal to } \\
4 \mathrm{~d} / \text { week }\end{array}$ & 1.02 & $0.73,1.42$ & $2 \cdot 21$ & $1.03,4 \cdot 75^{\star}$ & 1.39 & $0.61,3.15$ \\
\hline \multicolumn{8}{|l|}{ Adjustments } \\
\hline \multirow[t]{2}{*}{ Maternal age (years) } & $\geq 25$ (ref.) & - & - & - & - & - & - \\
\hline & $<25$ & 0.51 & $0.39,0.67^{*}$ & $1 \cdot 10$ & $0.62,1.95$ & 0.55 & $0.24,1.26$ \\
\hline \multirow[t]{2}{*}{ Child age (months) } & $\geq 24$ (ref.) & - & - & - & - & - & - \\
\hline & $<24$ & 0.87 & $0.66,1.13$ & 0.89 & $0.46,1.73$ & $2 \cdot 15$ & $1 \cdot 10,4 \cdot 20^{*}$ \\
\hline \multirow[t]{2}{*}{ Child gender } & Male (ref.) & - & - & - & - & - & - \\
\hline & Female & 1.07 & $0.85,1.35$ & 0.91 & $0.46,1.79$ & 0.90 & $0.43,1.89$ \\
\hline
\end{tabular}

OM/NC, overweight mother and child with normal height; NM/SSC, mother with normal weight and short-stature child; OM/SSC, overweight mother and short-stature child - double burden of malnutrition; ref., reference category. ${ }^{\star} P<0.05$.

families that did not have access to a variety of healthy foods and had a diet based on high-sugar foods and poor in fruit and vegetables ${ }^{(15)}$.

As shown in previous population research, our study revealed that low maternal educational level ( $0-8$ years of schooling) was associated with the double burden of malnutrition $^{(16)}$. However, another cross-sectional study conducted with 223 mother-child dyads in the rural area of Malaysia found no association between the double burden and maternal educational level ${ }^{(37)}$. There is a consensus that women with lower educational levels have lower participation in the labour market and have lower and unstable incomes. In addition, lower educational levels are associated with both greater inefficiency in allocating financial resources and lack of knowledge on buying healthy foods ${ }^{(38)}$. In this scenario, families often adopt compensatory feeding practices, such as increased consumption of fast food, soft drinks, canned goods and candies instead of consumption of foods with better nutritional quality due to the higher cost of the latter ${ }^{(39)}$; this fact can explain the overweight, especially among $\operatorname{adults}^{(40)}$, and height deficit among the children more vulnerable to nutritional deficiencies ${ }^{(41)}$ observed in studies evaluating these nutritional outcomes together. Lower maternal educational level is well known to be associated with children's impaired linear growth ${ }^{(42,43)}$, although our findings failed to show association with NM/SSC outcome. It is possible that other variables considered in the modelling process could have eliminated/diminished the negative impact of this variable on child growth.

In the present study, living in an inadequate household (non-masonry house) was associated with the double burden of malnutrition (OM/SSC) and growth deficit in children (NM/ SSC). There is no doubt that poor housing conditions promote higher risks of diseases and impaired nutritional status. The literature shows that undernutrition and obesity can coexist in homes with poor conditions ${ }^{(44)}$. The living condition is widely discussed and is strongly associated with household income which, as mentioned in many studies, defines the previous and current overall health status and the allocation of resources to purchase quality basic foods in quantities necessary for the healthy development and growth of individuals ${ }^{(45)}$. The current study also confirms the association between inadequate household (non-masonry house) and growth deficit (NM/SSC), corroborating the findings of other Brazilian studies conducted mainly in areas of high social vulnerability ${ }^{(46,47)}$. In children under 5 years old, the influence of environmental factors is much more relevant for the expression of growth potential than genetic factors ${ }^{(48)}$. Children living in households with poor floor and ceiling conditions and with no piped water and sewage systems have a higher incidence of recurrent infectious diseases that contribute to child undernutrition ${ }^{(49)}$.

Mothers with short stature were three times more likely to have a child with short stature, corroborating a study 
that also used the PNDS data set ${ }^{(23)}$ and other studies ${ }^{(50,51)}$. Mothers with short stature most likely provide a nutritionally restricted uterine environment; therefore, the fetus will have an inadequate supply of nutrients and restricted growth, which will result in low birth weight and short stature $^{(48)}$. The final adult height is likely influenced by genetic, environmental and social conditions experienced in childhood and poor maternal health, not only in developing countries but also in modern Western societies ${ }^{(51,52)}$.

In the present study, low vegetable intake was associated with the NM/SSC dyad, which is in agreement with the results obtained in a study conducted in the Republic of the Maldives with children under 5 years old ${ }^{(53)}$ and with other studies showing that inadequate intakes of vegetables, legumes and fruits, which are sources of micronutrients, in particular vitamins and minerals, can cause growth retardation, weight loss and increased susceptibility to infectious diseases in children ${ }^{(54)}$. The latest Brazilian Household Budget Survey (2008-2009) showed a high consumption of sandwiches and high-calorie drinks instead of fruit and vegetables among children, which makes this age group vulnerable to nutritional deficiencies and their multiple complications or co-morbidities, including growth deficit $^{(4)}$.

Another important result obtained in the present study was the fact that mothers who did not breast-feed were more likely to be overweight $(\mathrm{OM} / \mathrm{NC})$. A cohort study conducted in Pelotas, southern Brazil, with a 5-year follow-up showed that exclusive breast-feeding for 4 months was associated with a lower waist circumference and lower body fat percentage ${ }^{(55)}$. The results of another cohort study consisting of 315 women who were living in two cities of the Brazilian state of Bahia showed that breast-feeding for a period longer than 6 months was associated with weight loss ${ }^{(56)}$. A 9-month follow-up study performed in Brazil showed an association between longer duration of breast-feeding and lower postpartum weight retention ${ }^{(57)}$. Therefore, there are several studies demonstrating controversial results for the association between breast-feeding and postpartum weight loss. This fact can occur due to several reasons, such as the study design, the definition of the variable breast-feeding and its duration and intensity, the postpartum follow-up care of the women and the pre-pregnancy nutritional status, or the control of confounding variables involved in the analysis. One of the mechanisms that explains maternal weight loss during lactation is long duration and intensity of breast-feeding, which has a major influence on the maternal nutritional and energy demand for milk production and can contribute to up to $20 \%$ of total daily energy expenditure ${ }^{(58)}$. However, it must be considered that in the first months after delivery, high levels of prolactin cause an increased appetite to meet the energy demands of breast-feeding. If, on the one hand, weight loss is expected due to the high energy demands of lactation, on the other hand, one can expect an increase in weight due to increased appetite ${ }^{(59)}$.

The limitations of the present study include the fact that a cross-sectional design only allows for inferences to be made about a possible association between exposure factors and nutritional outcomes, and does not allow a causality relationship to be established. In addition, food intake variables can have a recall bias. The children's birth weight is an important predictor for morbidity and mortality in the age group of the studied children but could not be used due to the high number of missing responses. Despite this, we believe that those limitations could not be considered an alternative explanation for our results because the DHS includes a large sample of both rural and urban populations, is representative of the Brazilian population and includes potential determinants of dyad child-mother nutritional outcomes. In general, the findings are in agreement with similar studies, were analysed using appropriate statistical methods and controlled for significant confounding factors according to the conceptual model previously defined.

In summary, lower maternal education level and living in inadequate households were associated with the double burden of malnutrition. It is important to mention that the double burden outcome represents a grouping of opposite manifestations of malnutrition among individuals who share the same environment and household. Thus, it is believed that knowledge of potential determinants of the health of the mother-child dyad can contribute to establishing strategies promoting health and healthy diets by considering the two scenarios concomitantly (growth deficit and overweight). This situation was outlined in the nutritional transition process, with changes in demographics and morbidity/mortality profiles, which have been intensified in recent decades in developing countries.

It is essential that multidisciplinary teams in health promote educational activities about healthy eating and nutrition for the family, through health education; this is considered one of the most important strategies for the prevention of overweight and growth deficit, aiming to raise awareness on the importance of a diet rich in nutrients and low in saturated fats.

\section{Acknowledgements}

Financial support: T.G.-H. received a PhD scholarship from Coordenação de Aperfeiçoamento de Pessoal de Nível Superior (CAPES), Brazil and would also like to thank the Brazilian National Council of Research and Technology (CNPq) for a scholarship that supported a fellowship at the Federal University of Bahia, Brazil. Conflict of interest: None. Authorship: T.G.-H., R.C.R.-S. and R.L.F. planned the study, analysed the data, interpreted of results, wrote and reviewed the manuscript. M.L.B. and G.V.-M. planned the study, interpreted of results and revised the manuscript. All authors read and approved the final manuscript. 
Ethics of buman subject participation: The PNDS 2006 was approved by the Research Ethics Committees of the STD/AIDS Reference and Training Center of the São Paulo State Health Department, São Paulo, Brazil. All individuals who agreed to participate in the study signed an informed consent form.

\section{Supplementary material}

To view supplementary material for this article, please visit http://dx.doi.org/10.1017/S136898001600080X

\section{References}

1. Popkin BM, Adair LS \& Ng SW (2012) Global nutrition transition and the pandemic of obesity in developing countries. Nutr Rev 70, 3-21.

2. Finucane MM, Stevens GA, Cowan MJ et al. (2011) National, regional, and global trends in body-mass index since 1980: systematic analysis of health examination surveys and epidemiological studies with 960 country-years and 9.1 million participants. Lancet 377, 557-567.

3. Ministério da Saúde Brasil (2009) Pesquisa Nacional de Demografia e Saúde da Criança e da Mulher - PNDS 2006: Dimensões do Processo Reprodutivo e da Saúde da Criança. http://bvsms.saude.gov.br/bvs/publicacoes/pnds_crianca_ mulher.pdf (accessed March 2015).

4. Instituto Brasileiro de Geografia e Estatística (2010) Pesquisa de Orçamentos Familiares 2008-2009. Antropometria e Estado Nutricional de Crianças, Adolescentes e Adultos no Brasil. http://www.ibge.gov.br/home/estatistica/populacao/ condicaodevida/pof/2008_2009_encaa/pof_20082009_encaa. pdf (accessed March 2015).

5. Franks PW \& Ling C (2010) Epigenetics and obesity: the devil is in the details. BMC Med $\mathbf{8}, 88$.

6. Perez LM, Garcia K \& Herrera R (2013) Psychological, behavioral and familial factors in obese Cuban children and adolescents. MEDICC Rev 15, 24-28.

7. Godfrey KM, Gluckman PD \& Hanson MA (2010) Developmental origins of metabolic disease: life course and intergenerational perspectives. Trends Endocrinol Metab 21, 199-205.

8. Lee J, Houser RF, Must A et al. (2010) Disentangling nutritional factors and household characteristics related to child stunting and maternal overweight in Guatemala. Econ Hum Biol 8, 188-196.

9. Kourlaba G, Panagiotakos DB, Mihas K et al. (2009) Dietary patterns in relation to socio-economic and lifestyle characteristics among Greek adolescents: a multivariate analysis. Public Health Nutr 12, 1366-1372.

10. World Health Organization (2010) World Health Statistics 2010. http://www.who.int/whosis/whostat/2010/en/ (accessed March 2015).

11. Monteiro CA, Gomes FS \& Cannon G (2010) The snack attack. Am J Public Health 100, 975-981.

12. Doak CM, Adair LS, Bentley M et al. (2005) The dual burden household and the nutrition transition paradox. Int J Obes (Lond) 29, 129-136.

13. Doak CM, Adair LS, Monteiro C et al. (2000) Overweight and underweight coexist within households in Brazil, China and Russia. J Nutr 130, 2965-2971.

14. Lee J, Houser RF, Must A et al. (2012) Socioeconomic disparities and the familial coexistence of child stunting and maternal overweight in Guatemala. Econ Hum Biol 10, $232-241$.
15. Grijalva-Eternod CS, Wells JC, Cortina-Borja M et al. (2012) The double burden of obesity and malnutrition in a protracted emergency setting: a cross-sectional study of Western Sahara refugees. PLoS Med 9, e1001320.

16. Bassete MN, Romaguera D \& Gimenez MA (2014) Prevalence and determinants of the dual burden of malnutrition at the household level in Puna and Quebrada of Humahuaca, Jujuy, Argentina. Nutr Hosp 29, 322-330.

17. Monteiro CA, Szarfarc SC \& Mondini L (2000) Secular trends in childhood in the city of Sao Paulo, Brazil (1984-1996). Rev Saude Publica 34, Suppl. 6, S62-S72.

18. World Health Organization (2011) Childhood overweight and obesity. http://www.who.int/dietphysicalactivity/ childhood/en/ (accessed April 2016).

19. Aitsi-Selmi A (2015) Households with a stunted child and obese mother: trends and child feeding practices in a middle-income country, 1992-2008. Matern Child Health J 19, 1284-1291.

20. Garrett JL \& Ruel MT (2005) Stunted child-overweight mother pairs: prevalence and association with economic development and urbanization. Food Nutr Bull 26, 209-221.

21. Ochola S \& Masibo PK (2014) Dietary intake of schoolchildren and adolescents in developing countries. Ann Nutr Metab 64, Suppl. 2, 24-40.

22. Black RE, Allen LH, Bhutta ZA et al. (2008) Maternal and child undernutrition: global and regional exposures and health consequences. Lancet 371, 243-260.

23. Felisbino-Mendes MS, Matozinhos FP, Miranda JJ et al. (2014) Maternal obesity and fetal deaths: results from the Brazilian cross-sectional Demographic Health Survey, 2006. BMC Pregnancy Childbirth 14, 5.

24. World Health Organization (1995) Physical Status: The Use and Interpretation of Anthropometry. Report of a WHO Expert Committee. WHO Technical Report Series no. 854. Geneva: WHO.

25. Blackwell DL, Hayward MD \& Crimmins EM (2001) Does childhood health affect chronic morbidity in later life? Soc Sci Med 52, 1269-1284.

26. World Health Organization (2006) Child Growth Standards: Training Course on Child Growth Assessment. Module C: Interpreting growth indicators. Geneva: WHO.

27. Associação Brasileira de Empresas de Pesquisa (n.d.) Critério de Classificação Econômica Brasil (CCEB) 2012. http://www.abep.org/criterio-brasil (accessed April 2016).

28. Pérez-Escamilla R, Segall-Corrêa AM, Kurdian Maranha L et al. (2004) An adapted version of the US Department of Agriculture Food Insecurity module is a valid tool for assessing household food insecurity in Campinas, Brazil. J Nutr 134, 1923-1928.

29. World Health Organization (2004) Global Strategy on Diet, Physical Activity and Health: Fifty-Seventh World Health Assembly. Geneva: WHO.

30. Ceriello A, Quagliaro L, Piconi L et al. (2004) Effect of postprandial hypertriglyceridemia and hyperglycemia on circulating adhesion molecules and oxidative stress generation and the possible role of simvastatin treatment. Diabetes 53, 701-710.

31. Lopes-Garcia E, Schulze MB, Fung TT et al. (2004) Major dietary patterns are related to plasma concentrations for markers of inflammation and endothelial dysfunction. Am J Clin Nutr 80, 1029-1035.

32. Castro IRR, Cardoso LO, Egstrom EM et al. (2008) Vigilância de fatores de risco para doenças não transmissíveis entre adolescentes: a experiência da cidade do Rio de Janeiro, Brasil. Cad Saude Publica 24, 2279-2288.

33. Victora CG, Huttly SR, Fuchs SC et al. (1997) The role of conceptual frameworks in epidemiological analysis: a hierarchical approach. Int J Epidemiol 26, 224-227. 
34. Ferrer SR, Strina A, Jesus SR et al. (2008) A hierarchical model for studying risk factors for childhood diarrhoea: a case-control study in a middle-income country. Int $J$ Epidemiol 37, 805-815.

35. Strina A, Rodrigues LC, Cairncross S et al. (2012) Factors associated with rotavirus diarrhoea in children living in a socially diverse urban centre in Brazil. Trans $R$ Soc Trop Med Hyg 106, 445-451.

36. Dieffenbach S \& Stein AD (2012) Stunted child/overweight mother pairs represent a statistical artifact, not a distinct entity. J Nutr 142, 771-773.

37. Ihab AN, Rohana AJ, Manan WM et al. (2013) The coexistence of dual form of malnutrition in a sample of rural Malaysia. Int J Prev Med 4, 690-699.

38. de Souza Bittencourt L, Chaves dos Santos SM, de Jesus Pinto E et al. (2013) Factors associated with food insecurity in households of public school students of Salvador City, Bahia, Brazil. J Health Popul Nutr 31, 471-479.

39. Feinberg E, Kavanagh PL, Young RL et al. (2008) Food insecurity and compensatory feeding practices among urban black families. Pediatrics 122, 854-860.

40. Birbilis M, Moschonis G, Mougios V et al. (2013) Obesity in adolescence is associated with perinatal risk factors, parental BMI and sociodemographic characteristics. Eur J Clin Nutr 67, 115-121.

41. Sawaya AL (2006) Desnutrição: consequências em longo prazo e efeitos da recuperação nutricional. Estudos Avançados 20, 147-158.

42. Lakshman R, Zhang J, Zhang J et al. (2013) Higher maternal education is associated with favourable growth of young children in different countries. I Epidemiol Community Health 67, 595-602.

43. Hasan MT, Soares Magalhaes RJ, Williams GM et al. (2015) The role of maternal education in the 15-year trajectory of malnutrition in children under 5 years of age in Bangladesh. Matern Child Nutr (Epublication ahead of print version).

44. Sawaya AL, Solymos GMB, Florêncio TMdMT et al. (2003) Os dois Brasis: quem são, onde estão e como vivem os pobres brasileiros. Estudos Avançados 17, 21-44.

45. Drewnowski A (2009) Obesity, diets, and social inequalities. Nutr Rev 67, Suppl. 1, S36-S39.

46. Jesus GMd, Castelão ES, Vieira TdO et al. (2014) Déficit nutricional em crianças de uma cidade de grande porte do interior da Bahia, Brasil. Cienc Saude Colet 19, 1581-1588.
47. Silveira KBR, Alves JFR, Ferreira HS et al. (2010) Associação entre desnutrição em crianças moradoras de favelas, estado nutricional materno e fatores socioambientais (Association between malnutrition in children living in slums, maternal nutritional status, and environmental factors). $J$ Pediatr (Rio J) 86, 215-220.

48. Martorell R, Mendoza FS \& Castillo RO (1989) Genetic and environmental determinants of growth in MexicanAmericans. Pediatrics 84, 864-871.

49. Monteiro CA, Benicio MH, Konno SC et al. (2009) Causes for the decline in child under-nutrition in Brazil, 1996-2007. Rev Saude Publica 43, 35-43.

50. Addo OY, Stein AD, Fall CH et al. (2013) Maternal height and child growth patterns. J Pediatr 163, 549-554.

51. Ozaltin E, Hill K \& Subramanian SV (2010) Association of maternal stature with offspring mortality, underweight, and stunting in low- to middle-income countries. JAMA $\mathbf{3 0 3}$, 1507-1516.

52. Silventoinen K (2003) Determinants of variation in adult body height. J Biosoc Sci 35, 263-285.

53. Golder AM, Erhardt JG, Scherbaum V et al. (2001) Dietary intake and nutritional status of women and pre-school children in the Republic of the Maldives. Public Health Nutr 4, 773-780.

54. Kismul H, Van den Broeck J \& Lunde TM (2014) Diet and kwashiorkor: a prospective study from rural DR Congo. PeerJ 2, e350.

55. Gigante DP, Victora CG \& Barros FC (2001) Breastfeeding has a limited long-term effect on anthropometry and body composition of Brazilian mothers. J Nutr 131, 78-84.

56. da Silva MD, Oliveira Assis AM, Pinheiro SM et al. (2015) Breastfeeding and maternal weight changes during 24 months post-partum: a cohort study. Matern Child Nutr 11, 780-791.

57. Kac G, Benício MH, Velásquez-Meléndez G et al. (2004) Breastfeeding and postpartum weight retention in a cohort of Brazilian women. Am J Clin Nutr 79, 487-493.

58. Prentice AM \& Prentice A (1988) Energy costs of lactation. Annu Rev Nutr 8, 63-79.

59. Sichieri R, Field AE \& Rich-Edwards J (2003) Prospective assessment of exclusive breastfeeding in relation to weight change in women. Int $J$ Obes Relat Metab Disord 27, $815-820$ 